\title{
New Data and Methods in Accessibility Analysis
}

\author{
Ana Condeço-Melhorado ${ }^{1}$ - Aura Reggiani ${ }^{2}$. \\ Javier Gutiérrez ${ }^{1}$
}

Published online: 26 June 2018

(C) Springer Science+Business Media, LLC, part of Springer Nature 2018

Nowadays a large amount of data is available thanks to the widespread use of sensors and devices such as GPS, smartphones, credit cards, transport smart cards and bikesharing system cards. All these technologies generate massive geo-located data which is characterized by its high temporal and spatial resolution. These new sources of data can be used to monitor the movement of the population across space and time, estimate speeds and travel times on a network, measure social networks' intensity or analyze cities' daily dynamics. However, the use of these geo-located data sources in accessibility analysis is still in its infancy. In addition, the availability of digital networks provided by volunteers, public bodies and companies is growing rapidly. Google Maps, Open Street Map and navigation companies such as Here and TomTom offer very detailed data on road networks that can be used to provide a more accurate estimation of travel times in accessibility analysis, given their high spatial and temporal resolution. In the case of public transport, travel times can be calculated using GTFS (General Transit Feed Specification) files provided by transport authorities in different cities worldwide. New data and digital networks increase the quality of accessibility analysis, with promising applications to measure spatial and temporal variation of accessibility.

Meanwhile, in recent years, accessibility analysis has been extended with new methods and approaches, partly because of the availability of new data sources. From a spatial point of view, it is worth mentioning the advances in the areas of distance decay estimations (Östh and Reggiani 2014), the measurement of spatial spillovers (Gutiérrez et al. 2010; Álvarez-Ayuso et al. 2016), the integration of border effects (Salas-Olmedo et al. 2016), the study of network vulnerability (Jenelius et al. 2006; Susilawati 2012) or new land-use and transport models (Geurs and van Wee 2004). From an economic perspective, new studies have been published that relate accessibility with productivity, firm location and resilience (De Bok and Van Oort 2011;

Ana Condeço-Melhorado

acondeco@ucm.es

1 University Complutense of Madrid, Madrid, Spain

2 University of Bologna, Bologna, Italy 
Reggiani 2012; Holl 2016). Other studies have widened the scope of accessibility analysis to include a social perspective, looking at food deserts or the dynamic accessibility to services (Farber et al. 2014; Moya-Gómez and García-Palomares 2015; Boisjoly and El-Geneidy 2016) .

Figure 1 presents the eight papers included in this special issue, each of them providing several innovations regarding the use of novel sources of (big) data in accessibility analysis, new methodological approaches to accessibility modeling and economic and social accessibility analysis. Regarding the use of novel data sources, the following two studies provide interesting examples of how new (big) data can improve existing accessibility methods. Ziemke et al. (2017) test the reliability of OpenStreetMap data to compute accessibility in Nelson Mandela Bay in South Africa. Their study shows that a simpler accessibility indicator, calculated using OpenStreetMap data, performs equally as well as more complex accessibility measures (synthetic population) that require more detailed information from Census and travel surveys. Also, considering new data sources, TomTom and Twitter data for the city of Madrid is used by Moya-Gómez et al. (2017) to measure the changing accessibility conditions due to variations in transport and the attractiveness of destination zones. These accessibility changes are due to varying congestion conditions and different users' daily activities. Results reveal different accessibility profiles for different zones, suggesting that specific urban planning measures are required depending on the spatial patterns of accessibility conditions.

In addition to the empirical advances coming about due to the existence of big datasets, theory and methods are still important in most of our case studies. Therefore, we include two methodological papers. The first one looks at the complex relationship between transport and land use and how these influence accessibility (Stępniak and Rosik 2017). They use a road and population panel dataset in Poland (1995-2015) and test the role of distance decay functions in accessibility changes and the importance of transport and land-use (population) variations. Results show the major influence of distance decay in both components, in terms of absolute change and regional

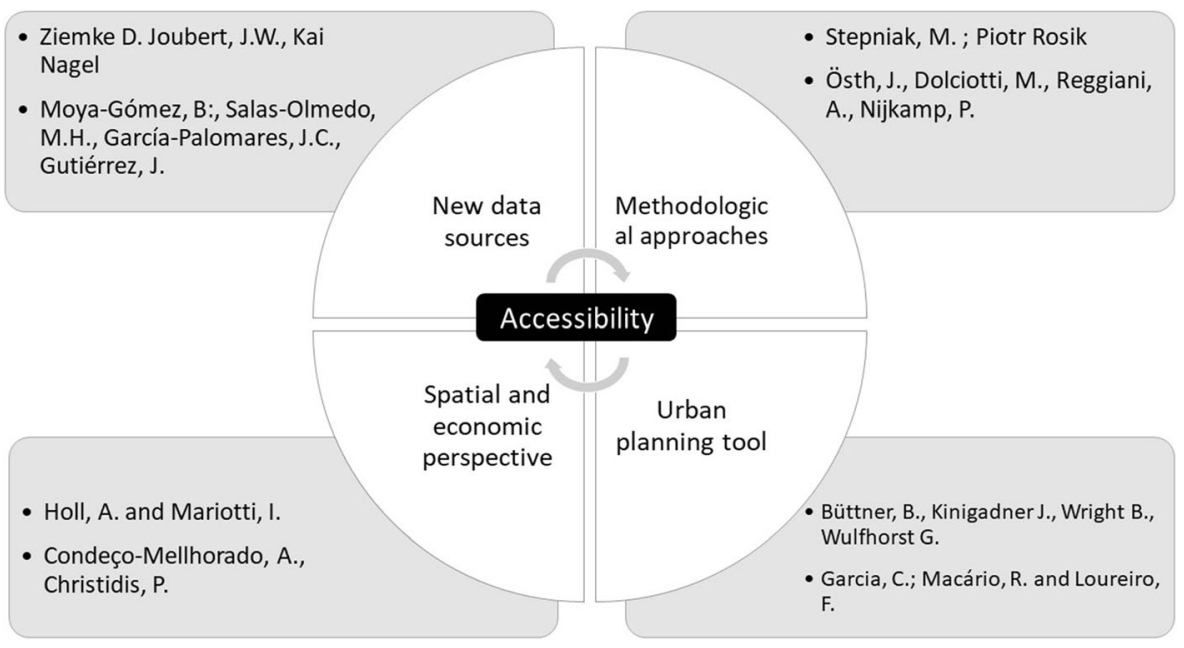

Fig. 1 Papers presented in this special issue 
accessibility disparities. The second study uses longitudinal, individual level statistics regarding the labor market, education, and social sectors. Östh et al. (2018) present a novel approach to measure social capital, looking at the relationship between resilience capacity of urban areas, social capital and accessibility. A quantile regression model is applied to analyze the relation between socio-economic factors and accessibility, with different levels of social capital.

From a spatial and economic perspective, Holl and Mariotti (2017) consider the relation between accessibility and company location by focusing on logistic firms in Spain and the interplay between company location, accessibility and urban structure. The analysis is performed using a dataset of georeferenced firm level data and a highly detailed road network, showing that company location is greatly determined by accessibility conditions and proximity to urban spaces. Also using a geographical focus, Condeço-Melhorado and Christidis (2017) use a road and population panel dataset covering fifty years (1960-2010) for the border regions of Portugal, Spain and France. The accessibility of regions located near national borders has not received much attention from scholars to date, even though it constitutes an important integration factor in regional economies such as the European Union. The market potential and daily accessibility indicators are jointly used to offer a complementary view to the assessment of access conditions in border regions. Outcomes show that areas located near national borders have been catching up with the other regions in their countries, both in terms of national and international accessibility.

Accessibility measures can also be used as a planning tool to solve specific urban problems, as in the case of Munich and its metropolitan area, which faces many challenges due to the increase in population and tourism. Büttner et al. (2018) provide several examples of accessibility analysis that improve the planning of land-use and transport actions. Their study presents an accessibility atlas, highlighting priority areas in terms of public transport needs and access inequalities. Likewise, Garcia et al. (2018) advocate the use of accessibility analysis to enhance transport and mobility conditions in urban areas. They show important disparities in terms of access to jobs and mobility patterns, both in private and public transport modes in Lisbon. Their approach offers a strategic view of areas in need of policies with a better focus in order to ensure more equitable levels of accessibility and mobility.

All these studies are good examples of how methodological advances in the field of accessibility analysis can be achieved both from improved data or new theoretical approaches, thereby contributing to better transport and territorial planning.

\section{References}

Álvarez-Ayuso IC, Condeço-Melhorado AM, Gutiérrez J, Zofío JL (2016) Integrating network analysis with the production function approach to study the spillover effects of transport infrastructure. Reg Stud 50(6)

Boisjoly G, El-Geneidy A (2016) Daily fluctuations in transit and job availability: a comparative assessment of time-sensitive accessibility measures. J Transp Geogr 52:73-81

Büttner B, Kinigadner J, Ji C, Wright B, Wulfhorst G (2018) The TUM accessibility atlas: visualizing spatial and socioeconomic disparities in accessibility to support regional land-use and transport planning. Netw Spat Econ :1-30

Condeço-Melhorado A, Christidis P (2017) Road accessibility in border regions: a joint approach. Netw Spat Econ 
De Bok M, Van Oort F (2011) Agglomeration economies, accessibility and the spatial choice behavior of relocating firms. J Transp Land Use 4(1):5

Farber S, Morang MZ, Widener MJ (2014) Temporal variability in transit-based accessibility to supermarkets. Appl Geogr 53:149-159

Garcia CSHF, Macário MR, de Menezes EDAG, Loureiro CFG (2018) Strategic assessment of Lisbon's accessibility and mobility problems from an equity perspective. Netw Spat Econ :1-25. https://doi. org/10.1007/s11067-018-9391-4

Geurs KT, van Wee B (2004) Accessibility evaluation of land-use and transport strategies: review and research directions. J Transp Geogr 12(2)

Gutiérrez J, Condeço-Melhorado A, Martín JC (2010) Using accessibility indicators and GIS to assess spatial spillovers of transport infrastructure investment. J Transp Geogr 18(1)

Holl A (2016) Highways and productivity in manufacturing firms. J Urban Econ 93:131-151

Holl A, Mariotti I (2017) The geography of logistics firm location: the role of accessibility. Netw Spat Econ :1-25

Jenelius E, Petersen T, Mattsson L-G (2006) Importance and exposure in road network vulnerability analysis. Transp Res A Policy Pract 40(7):537-560

Moya-Gómez B, García-Palomares JC (2015) Working with the daily variation in infrastructure performance on territorial accessibility. The cases of Madrid and Barcelona. Eur Transp Res Rev 7(2)

Moya-Gómez B, Salas-Olmedo MH, García-Palomares JC, Gutiérrez J (2017) Dynamic accessibility using big data: the role of the changing conditions of network congestion and destination attractiveness. Netw Spat Econ :1-18

Östh J, Reggiani A, Galiazzo G (2014) Novel methods for the estimation of cost-distance decay in potential accessibility models. In Accessibility and Spatial Interaction, 15-37. Edward Elgar Publishing

Östh J, Dolciotti M, Reggiani A, Nijkamp P (2018) Social capital, resilience and accessibility in Urban Systems: a study on Sweden. Netw Spat Econ :1-24

Reggiani A (2012) Accessibility, connectivity and resilience in complex networks. In Accessibility analysis and transport planning, ed. K. J. K. and A. R. Karst T. Geurs, 15-36. Edward Elgar Publishing

Salas-Olmedo M, García-Alonso P, Gutiérrez J (2016) Distance deterrence, trade barriers and accessibility. an analysis of market potential in the European Union. EJTIR 16(2):319-343

Stępniak M, Rosik P (2017) The role of transport and population components in change in accessibility: the influence of the distance decay parameter. Netw Spat Econ :1-22

Susilawati (2012) Remoteness and accessibility in the vulnerability analysis of regional road networks. Transp Res A Policy Pract 46(5):761-771

Ziemke D, Joubert JW, Nagel K (2017) Accessibility in a post-Apartheid City: comparison of two approaches for accessibility computations. Netw Spat Econ :1-31 